\title{
One-Pot Synthesis of Heteroatom-Bridged Cyclic Diaryliodonium Salts
}

Mattis Damrath ${ }^{\mathrm{a}}$, Lucien D. Caspers ${ }^{\mathrm{a}}$, Daniel Duvinage ${ }^{\mathrm{b}}$ and Boris J. Nachtsheim ${ }^{\text {a* }}$

aInstitute for Organic and Analytical Chemistry, University of Bremen, 28359 Bremen, Germany, phone: +49 $421218-63113$

bInstitute for Inorganic Chemistry and Crystallography, University of Bremen, 28359 Bremen, Germany, phone: +49 421 218-63155

Prof. Dr. Boris J. Nachtsheim, nachtsheim@uni-bremen.de

\section{Abstract}

Two one-pot procedures for the construction of $\mathrm{O}$ - and $\mathrm{N}$-bridged diaryliodonium triflates are described. An effective aryne-mediated arylation of o-iodophenols and -sulfonamides provides diarylether and diarylamine intermediates, which are subsequently oxidized and cyclized to the corresponding diaryliodaoxinium and -iodazinium salts. Different derivatizations were applied to demonstrate their capacity as useful building blocks and gain a deeper understanding towards the general reactivity of these underdeveloped but potentially highly useful compounds.

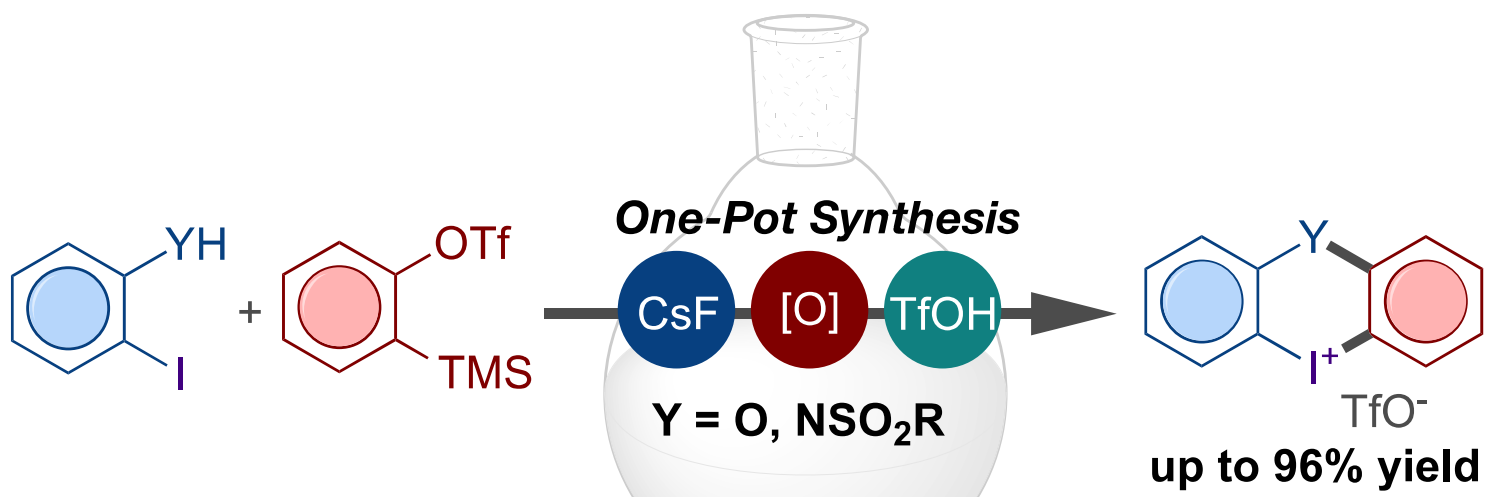




\section{Keywords}

hypervalent iodine $\cdot$ iodonium salts - one-pot synthesis $\cdot$ heterocycles $\bullet$ arynes • arylation

\section{Introduction}

Hypervalent iodine compounds (iodanes) have found widespread applications as electrophilic group transfer reagents, ${ }^{[1]}$ as mild oxidants for the synthesis of natural products $^{[2]}$ and in organo- and photocatalysis. ${ }^{[3]}$ Diaryliodonium salts are an important subclass among iodanes, which are commonly applied as electrophilic arylation reagents for transition-metal-catalyzed and metal-free arylations. ${ }^{[4]}$ In this regard, cyclic diaryliodonium salts which are characterized by two aryl moieties directly connected or bridged with carbon or heteroatoms have been utilized for the effective synthesis of mono- and double-functionalized diaryl-based molecules through regioselective ring opening with a wide range of nucleophiles. ${ }^{[5]}$ They can also be applied as starting materials for the synthesis of annulated hetero- and carbocycles. While carbon-based iodonium salts have been well studied, their heteroatom-bridged counterparts are underrepresented due to the low availability of efficient synthetic protocols. The first synthesis of $\mathrm{O}$ - and $\mathrm{N}$-bridged cyclic iodonium salts was developed by Behringer et al. (Scheme 1, a), starting from diphenylether or -amine scaffolds. In a two-step procedure, the corresponding oxidized iodane was isolated and subsequent cyclization of the oxidized intermediate with sulfuric acid gave the desired cyclic iodonium salts. ${ }^{[6]}$ Modern approaches towards iodaoxinium salts based on preexisting iodinated diarylethers have been described by Wen and Huber. ${ }^{[7-8]}$ Due to the growing interest of these reactive compounds, efficient and reliable procedures for their efficient synthesis are highly desirable.

Our group is interested in the synthesis and reactivity of novel cyclic iodonium salts as well as their use in catalysis. We developed two one-pot procedures for the synthesis of carbon-bridged cyclic iodonium salts. ${ }^{[9]}$ Based on these recent findings, we now want to report a unique one-pot synthesis of $O$ - and $N$-bridged iodonium triflates 1 and 2 by treating substituted phenols and anilines with in situ generated arynes (Scheme 1, b). 
a) Known approaches<smiles>[R]c1ccc([Y]c2ccc([R])cc2I)cc1</smiles><smiles>[Y][Y]1c2ccc([R])cc2[I+]c2cc([R])ccc21</smiles>

$$
\begin{aligned}
& Y=O, N A c ; X=H_{4} O_{4} R=H, N_{2}(\text { Behringer, 1965) } \\
& Y=O ; X=\mathrm{HSO}_{4} ; R=M e, \mathrm{CO}_{2} \mathrm{Me}, \mathrm{NO}_{2}(\text { Wen, 2016) } \\
& Y=O ; X=\mathrm{TfO} ; \mathrm{R}=\mathrm{F} \text { (Huber, 2021) }
\end{aligned}
$$

b) This work: New one-pot approach
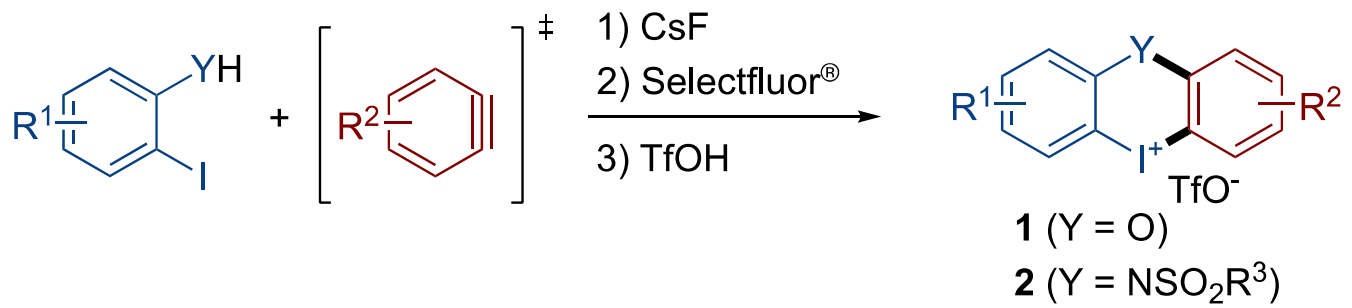

Scheme 1. Synthesis of heteroatom-bridged diaryliodonium salts. 


\section{Results and Discussion}

To accomplish the proposed one-pot reaction we intended to utilize reactive aryne intermediates as arene electrophiles for achieving a metal-free $\mathrm{C}\left(\mathrm{sp}_{2}\right)-\mathrm{O}$ and $-\mathrm{N}$ coupling. ${ }^{[10]}$

For the initial aryne-mediated arylation of o-iodophenols 3, preliminary investigations revealed a procedure using $\mathrm{CsF}$ in $\mathrm{MeCN}$ as the most effective coupling strategy with (trimethylsilyl)aryl triflates $\mathbf{4}$ as aryne precursors to obtain diphenylether scaffolds $\mathbf{5}$ (Table 1, a). ${ }^{[11]}$ For the second step of this one-pot reaction, the oxidation (b) and cyclization (c) sequence with the most prominent oxidants (see Table S1, Supporting Information (SI)) were screened. We were able to establish Selectfluor ${ }^{\circledR}$ as the most effective oxidant. It was the only oxidant that resulted in quantitative oxidation of the intermediate $\mathbf{5 a}$ to $\mathbf{6 a}$. A quantitative transformation was necessary since an incomplete oxidation resulted in the undesired formation of acyclic iodonium salts due to the electron-donating character of diphenylether motifs.

Table 1. Optimization of the One-Pot Procedure with Selectfluor ${ }^{\circledR}$ as Oxidant.

\begin{tabular}{|c|c|c|c|c|c|c|c|}
\hline $3 a-b$ & & & $5 a-b$ & & a-b & & 1a-b \\
\hline \multirow{2}{*}{ entry ${ }^{[a]}$} & \multirow{2}{*}{$\mathrm{R}$} & $\mathrm{t}_{b}^{[\mathrm{b}]}$ & acid & $\mathrm{T}_{c}^{[c]}$ & $\mathrm{T}_{c}^{[c]}$ & \multirow{2}{*}{ additive } & yield of 1 \\
\hline & & $/ \mathrm{h}$ & (eq.) & $1{ }^{\circ} \mathrm{C}$ & $/ \mathrm{h}$ & & $(\%)^{[\mathrm{d}]}$ \\
\hline 1 & $\mathrm{H}(\mathbf{3 a})$ & 24 & $\mathrm{BF}_{3} \cdot \mathrm{OEt}_{2}(4.0)$ & RT & 1 & - & $35^{[\mathrm{e}]}$ \\
\hline 2 & $\mathrm{H}$ & 24 & $\mathrm{BF}_{3} \cdot \mathrm{OEt}_{2}(4.0)$ & 0 & 2 & - & 42 \\
\hline 3 & $\mathrm{H}$ & 24 & $\mathrm{BF}_{3} \cdot \mathrm{OEt}_{2}(4.0)$ & -40 & 4 & - & 52 \\
\hline 4 & $\mathrm{H}$ & 24 & $\mathrm{BF}_{3} \cdot \mathrm{OEt}_{2}(4.0)$ & $-40-80$ & 5 & $\mathrm{AcOH}$ & 62 \\
\hline 5 & $\mathrm{H}$ & 24 & $\begin{array}{c}\mathrm{BF}_{3} \cdot \mathrm{OEt}_{2}(4.0) \\
\mathrm{TfOH}(1.5)\end{array}$ & $-40-80$ & 2 & $\mathrm{AcOH}$ & 78 \\
\hline 6 & $\mathrm{H}$ & 24 & $\begin{array}{c}\mathrm{BF}_{3} \cdot \mathrm{OEt}_{2}(4.0) \\
\mathrm{TfOH}(1.5)\end{array}$ & $0-80$ & 2 & $\mathrm{AcOH}$ & 74 \\
\hline 7 & H & 24 & TfOH (4.0) & $0-80$ & 2 & $\mathrm{AcOH}$ & 81 \\
\hline 8 & $\mathrm{Br}(3 b)$ & 48 & $\mathrm{BF}_{3} \cdot \mathrm{OEt}_{2}(4.0)$ & $-40-80$ & 5 & $\mathrm{AcOH}$ & 24 \\
\hline
\end{tabular}


[a] General reaction conditions: Step a): 3 (0.100 mmol), 4a (1.5 eq.), CsF (3.0 eq.), MeCN (1.6 mL), rt. Step b): Addition of Selectfluor ${ }^{\circledR}\left(4.0\right.$ eq.). Step c): Addition of acid. ${ }^{[b]}$ Time for oxidation step. ${ }^{[c]}$ Temperature and time for cyclization step. ${ }^{[d]}$ Purity $>97 \%$. ${ }^{[e]}$ Purity around $85 \%$ to $90 \%$. ${ }^{[f]}$ Addition of Selectfluor ${ }^{\circledR}$ (2.0 eq.) after $24 \mathrm{~h}$ in Step 2.

Using exclusively Selectfluor ${ }^{\circledR}$ throughout the following experiments we started further optimizations with o-iodophenol $(3 a, R=H$, Table 1$)$ as the model substrate. Coupling with the aryne precursor $4 \mathrm{a}$, subsequent oxidation for $24 \mathrm{~h}$ and cyclization with 4.0 equiv. $\mathrm{BF}_{3} \cdot \mathrm{OEt}_{2}$ at room temperature yielded the desired iodaoxinium salt $\mathbf{1 a}$ in $35 \%$ yield (entry 1 ) as the triflate salt. When the cyclization step was performed at $0{ }^{\circ} \mathrm{C}$ the yield increased to $42 \%$ (entry 2). At $-40{ }^{\circ} \mathrm{C}$ the desired product was obtained in $52 \%$ yield (entry 3). The use of $\mathrm{AcOH}$ as additive for the oxidation step resulted in a significantly diminished side product formation, most likely due to the formation of the more stable bisacetoxy $\mathrm{I}(\mathrm{III})$ derivate $\mathbf{6 a}(\mathrm{L}=\mathrm{OAc})$. This finally resulted in an improved formation of 1a (62\% yield, entry 4). A further significant improvement was achieved through addition of $\mathrm{TfOH}$ during the cyclization step which increased the yield of $1 \mathrm{a}$ to $78 \%$ (entry 5 ). Performing the cyclization at $0{ }^{\circ} \mathrm{C}$ resulted in a diminished yield (entry 6). Further replacement of $\mathrm{BF}_{3} \cdot \mathrm{OEt}_{2}$ with $\mathrm{TfOH}$ further increased the yield of $\mathbf{1 a}$ to satisfying $81 \%$ (entry 7 ).

We then explored the addressable substrate scope under these optimized conditions. Performing the reaction on a $5 \mathrm{mmol}$ scale gave 1a in $81 \%$ yield (Scheme 2). With the electron-poor bromo-substituted substrate $\mathbf{3 b}$, we observed a significant drop in yield (entry 8), possibly due to a diminished stability of the I(III) intermediate. To circumvent this issue, addition of two equivalents of the oxidant after an initial oxidation period was necessary to increase the yield of $\mathbf{1 b}$ to $74 \%$ (entry 9 ). These slightly modified conditions were then consequently applied for all electron poor substrates. The strong electron-poor $4-\mathrm{NO}_{2}$ derivate $1 \mathrm{c}$ was isolated in a moderate yield of $57 \%$.

Slightly activated derivates bearing 4-Me- and 4-tBu-substituents $1 \mathrm{~d}$ and $1 \mathrm{e}$ were obtained in up to $68 \%$ yield. The more electron-rich 4 -OMe-substituted derivate gave an inseparable product mixture of $\mathbf{1 f}$ after the cyclization step. The $\mathrm{Cl}$ - and Fsubstituted derivates $\mathbf{1 g}$ and $1 \mathrm{~h}$ were yielded under the slightly optimized conditions 


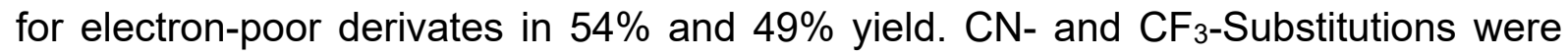
viable as well and subsequently $1 \mathbf{i}$ and $\mathbf{1 j}$ were obtained in up to $70 \%$ yield. Here, the cyclization step resulted in a decomposition of the oxidized intermediate. A 4-phenylsubstituted derivative $1 \mathbf{k}$ did not react at all. A variation of the substitution pattern was feasible as 2-Br, 3-Br and 5- $\mathrm{Br}$ derivates $11-\mathrm{n}$ were isolated in $39 \%$ to $63 \%$ yield. This indicated that electronic or steric effects from substituents close to the bridge atoms may be relevant in the oxidation step. Also limitations of the method were visible for extended $\pi$-systems, as already observed for $\mathbf{1 k}$, but also for the naphyhtyl-derivative 10.

The lowered yield of the 2-Br-4-methyl derivate $1 \mathrm{p} \mathrm{(50 \% )} \mathrm{in} \mathrm{comparison} \mathrm{to} 1 \mathrm{~d}$ verified the effects of substituents next to the iodacycle. The reaction of $3 \mathbf{a}$ with a dimethylsubstituted (trimethylsilyl)aryl triflate $\mathbf{4 b}$ yielded $\mathbf{1 q}$ in $\mathbf{9 1 \%}$.

Aryne precursors with other substitution patterns or more electron-donating or electron-withdrawing groups were challenging due to an inseparable isomer formation and decomposition in the cyclization step. A complete list of all substrates that could not be successfully synthesized are found in the SI (Figure S2).

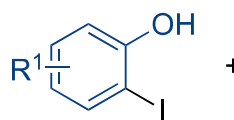

3

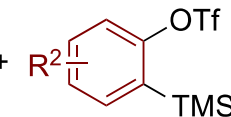

4
1) $\mathrm{CsF}$ (3.0 eq.), $\mathrm{MeCN}, \mathrm{rt}, 24 \mathrm{~h}$

2) Selectfluor ${ }^{\circledR}(4.0-6.0$ eq. $)$,

$\mathrm{AcOH}, \mathrm{rt}, 24-48 \mathrm{~h}$

3) $\mathrm{TfOH}$ (4.0 eq.), $0-80^{\circ} \mathrm{C}, 2-5 \mathrm{~h}$

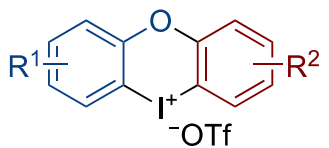

1

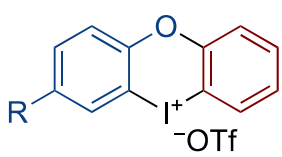

1a: $R=H, 81 \%, 81 \%[a]$

1b: $\mathrm{R}=\mathrm{Br}, 74 \%[\mathrm{~b}]$

1c: $\mathrm{R}=\mathrm{NO}_{2}, 57 \%[\mathrm{~b}]$

$1 \mathrm{~d}: \mathrm{R}=\mathrm{Me}, 68 \%$

1e: $R=t B u, 49 \%$

1f: $\mathrm{R}=\mathrm{OMe}, 0 \%$

1g: $\mathrm{R}=\mathrm{Cl}, 54 \%[\mathrm{~b}]$

1h: $R=F, 49 \%[b]$

1i: $\mathrm{R}=\mathrm{CN}, 70 \%{ }^{[\mathrm{b}]}$

$1 \mathrm{j}: \mathrm{R}=\mathrm{CF}_{3}, 61 \%{ }^{[\mathrm{b}]}$

1k: $\mathrm{R}=\mathrm{Ph}, 0 \%$

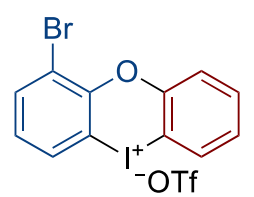

1I: $42 \%^{[\mathrm{b}]}$

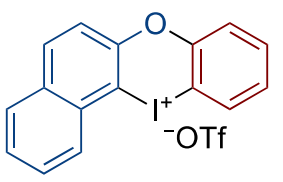

10: $0 \%$<smiles>[OH+][I+]1c2ccccc2Oc2cc(Br)ccc21</smiles>

1m: $63 \%{ }^{[b]}$

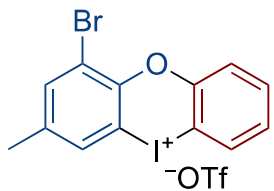

1p: $50 \%\left[{ }^{[b]}\right.$<smiles>[OH+][I+]1c2ccccc2Oc2cccc(Br)c21</smiles>

1n: $39 \%{ }^{[b]}$<smiles>Cc1ccc(C)c2c1Oc1ccccc1[I+]2[OH+]</smiles>

1q: $91 \%$

Scheme 2. Substrate scope using the optimized conditions of Table 1. General reaction conditions: Step 1: 3 (0.100 mmol), 4 (1.5 eq.), CsF (3.0 eq.), MeCN (1.6 mL), rt. Step 2: Selectfluor ${ }^{\circledR}$ (4.0 eq.), AcOH $(0.5 \mathrm{~mL})$, rt. Step 3: $\mathrm{TfOH}$ (4.0 eq.), $0-80^{\circ} \mathrm{C}$. ${ }^{\text {a] }}$ Reaction was performed on a $5.00 \mathrm{mmol}$ scale. ${ }^{[b]}$ Addition of Selectfluor ${ }^{\circledR}$ (2.0 eq.) after $24 \mathrm{~h}$ in Step 2. 
As we were also interested in the synthesis of $\mathrm{N}$-bridged diaryliodonium salts, we additionally investigated $\mathrm{N}$-tosylsulfonamide $7 \mathrm{a}$ with $\mathbf{4 a}$ as aryne source under slightly different conditions for the arylation step (Scheme 3). The desired product 2a was obtained in a high yield of $92 \%$ without any further optimizations. Therefore, we started to investigate the scope and the scalability of this reaction. Performing the reaction on a $5 \mathrm{mmol}$ scale gave $2 \mathrm{a}$ in a slightly improved yield of $96 \%$.

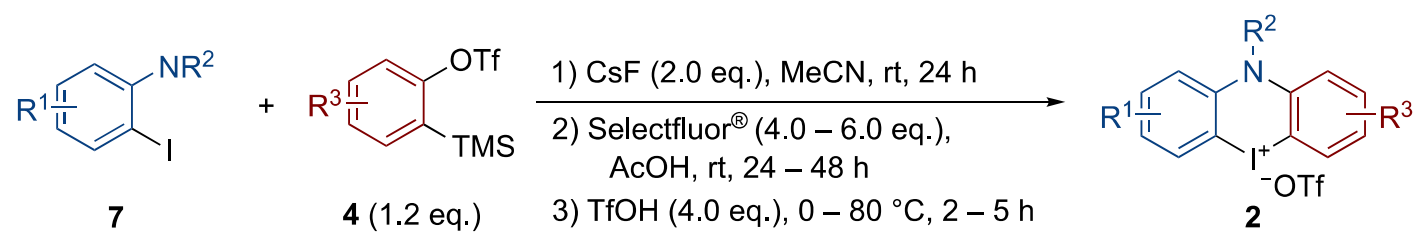

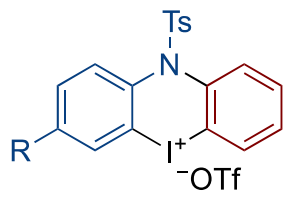

2a: $R=H, 92 \%, 96 \%$ [a]

2b: $R=M e, 88 \%$

2c: $\mathrm{R}=\mathrm{OMe}, 0 \%$

2d: $\mathrm{R}=\mathrm{Br}, 86 \%[\mathrm{~b}]$

2e: $R=F, 86 \%[b]$

2f: $\mathrm{R}=\mathrm{CF}_{3}, 77 \%[\mathrm{~b}]$

2g: $\mathrm{R}=\mathrm{NO}_{2}, 67 \%[\mathrm{~b}]$

2h: $\mathrm{R}=\mathrm{CN}, 76 \%$ [b]

2i: $\mathrm{R}=\mathrm{Ph}, 83 \%$

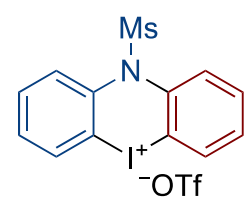

2j: $83 \%, 92 \%[a]$<smiles></smiles>

2k: $79 \%$

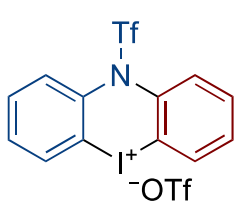

2I: $0 \%$<smiles>Clc1cc(Cl)c2c(c1)[I+][OH+]c1ccccc1N2[AsH3-]</smiles>

$2 m: 62 \%{ }^{[b]}$<smiles>[Al-]N1c2ccccc2[I-]c2c1ccc1ccccc21</smiles>

2n: $44 \%$

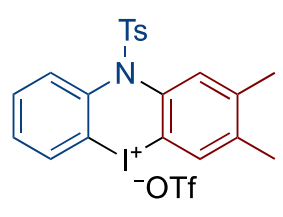

2o: $45 \%$<smiles></smiles>

2p: $71 \%$<smiles>COc1ccc2c(c1)N([13CH3])c1ccccc1[I-]2[OH+]</smiles>

2q: $45 \%$

Scheme 3. Substrate scope. General reaction conditions: Step 1: 7 (0.100 mmol), 4 (1.2 eq.), CsF (2.0 eq.), MeCN (1.6 mL), rt. Step 2: Selectfluor ${ }^{\circledR}$ (4.0 eq.), AcOH (0.5 mL), rt. Step 3: TfOH (4.0 eq.), $0-80^{\circ}$ C. ${ }^{[a]}$ Reaction was performed on a $5.00 \mathrm{mmol}$ scale. ${ }^{[b]}$ Addition of Selectfluor ${ }^{\circledR}$ (2.0 eq.) after $24 \mathrm{~h}$ in Step 2.

We then investigated a variety of substituents at the aryl moiety of the sulfonamide. While the 4-Me-substituted derivate $\mathbf{2 b}$ could be obtained with a yield of $88 \%$, OMe substitution resulted in a decomposition of $\mathbf{2 c}$ as already observed for the $\mathrm{O}$-bridged diaryliodonium triflate 1f. For desactivated substrates it was again necessary to apply further amounts of oxidant after an initial oxidation time. Under these modified conditions, $\mathrm{Br}$ - and $\mathrm{F}$-substituted derivates $\mathbf{2} \mathbf{d}$ and $\mathbf{2 e}$ were obtained in up to $86 \%$ yield. 
Electron-poor substrates such as $\mathrm{NO}_{2-}, \mathrm{CF}_{3-}$ and $\mathrm{CN}$-substituted salts $\mathbf{2 f - h}$ were isolated in yields of up to $77 \%$. In comparison to their oxygen analogs, the synthesis of the phenyl-substituted diaryliodazinium triflate was successful yielding $2 \mathbf{i}$ in $83 \%$. Using methyl sulfonamide, the product $\mathbf{2} \mathbf{j}$ was obtained in $83 \%$ yield on a small scale and $92 \%$ yield on a $5.0 \mathrm{mmol}$ scale. Mesityl sulfonamide-substituted triflate $\mathbf{2 k}$ was isolated in $79 \%$. With $\mathrm{R}^{2}=\mathrm{Tf}$, a complex mixture was obtained during the cyclization step and $2 \mathbf{l}$ could not be further purified. Substrates with two electron-withdrawing substituents such as bis-Cl-disubstituted diphenylamines were viable for a selective cyclization yielding $\mathbf{2 m}$ in $63 \%$ yield. Finally, the naphthalene-substituted diaryliodazinium triflate $2 \mathrm{n}$ was isolated in $44 \%$ yield.

The modified heteroatom bridge allowed the coupling with different trimethylsilyl(aryl) triflates 4 . The reaction of $7 a$ with various dimethyl-substituted aryne precursors $4 \mathbf{b}$ and $\mathbf{4 c}$ successfully provided $2 \mathrm{o}$ and $\mathbf{2 p}$ in $71 \%$ and $45 \%$ yield. The reaction with $\mathbf{4 d}$ yielded the methoxy-substituted triflate $2 q$ in $45 \%$ yield, indicating that a strong electron-donating group may be relevant during the oxidation/cyclization sequence. However, the developed method offers a fast alternative for the syntheses of a broad range of diaryliodaoxinium and -azinium triflates. Although there are still intrinsic issues for the selective synthesis of some diarylether or -amine scaffolds through arynemediated arylation, our effective oxidation/cyclization sequence can be used to achieve further heteroatom-bridged derivates.

Single crystals for the oxygen-bridged iodonium triflates $\mathbf{1 a}$ and $\mathbf{1 b}$ as well as the nitrogen-bridged derivate $2 a$ to verify their solid-state structures were obtained (Figure 1). All structures show the typical, slightly distorted T-shaped structure which is commonly observed for I(III) derivates with a C-I-O angle close to $170^{\circ}$ and a C-I-C angle close to $90^{\circ}$. An intramolecular interaction of the internal heteroatom to the iodine center could not be identified since the I-O distance is for all structures approximately $0.3 \AA$ higher than to the corresponding external oxygen of the triflate.

Furthermore, it should be emphasized that in case of diaryliodazinium triflate $\mathbf{2 a}$ a significant $\pi$-coordination of the tosyl arene ring to the $\mathrm{I}(\mathrm{III})$ center was observed (3.6 А). 


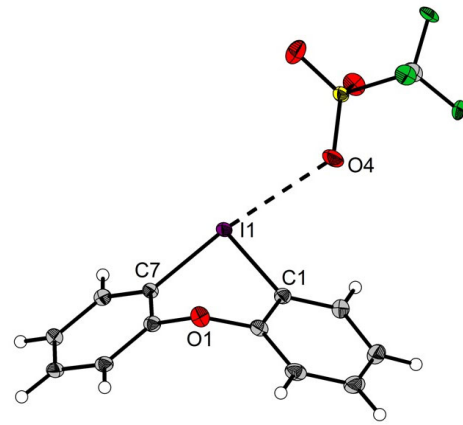

1a (CCDC 2111398)

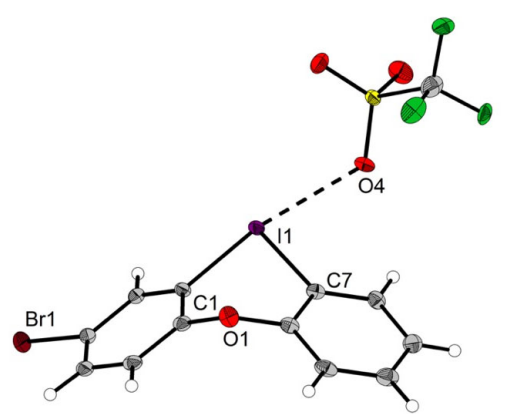

1b (CCDC 2111397)

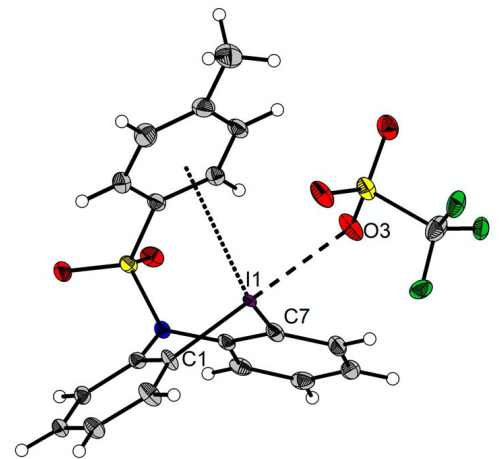

2a (CCDC 2111396)

Figure 1. X-Ray structures (ORTEP drawing) for cyclic iodonium triflates $\mathbf{1 a}, \mathbf{1 b}$ and $\mathbf{2 a}$ with thermal ellipsoids displayed with $50 \%$ probability. Selected bond length and angles for 1a (CCDC 2111398): I1C7: $2.0913 \AA$, I1-C1: 2.0888 A, I1-O4 2.8175 A, I1-O1 3.1016 A, C1-I1-C7 88.24 , C7-I1-O4 167.051. Selected bond length and angles for 1b (CCDC 2111397): I1-C1: 2.0897 A, I1-C7: 2.0943 $\AA$, I1-O4 $2.7370 \AA, I 1-013.1321 \AA, C 1-11-C 789.11^{\circ}, C 1-11-04170.034^{\circ}$. Selected bond length and angles for 2a (CCDC 2111396): C1-I1: 2.1204 A, C7-I1: $2.0992 \AA$, I1-O3: $2.7316 \AA$ I1-N1 3.1447 A, I1-Tosyl: 3.6480 A, C1-I1-C7: 89.73, C7-I1-O3: 77.497º, C1-I1-O3 165.167º.

To demonstrate the utilization of these novel iodonium salts as reactive synthetic building blocks and to get further insights into their reactivity, a variety of derivatizations were investigated (Scheme 4). Copper-catalyzed ring opening of the diphenyliodaoxinium triflate 1a with TBAI yielded the desired diiodo derivate 8 in $73 \%$ yield. ${ }^{[12]}$ Counterion exchange ${ }^{[13]}$ was achieved by treating a hot solution of the triflate derivate with an aqueous solution of $\mathrm{KBr}$. Subsequent thermolysis ${ }^{[14]}$ of the resulting bromide salt resulted in the formation of 9 in $49 \%$ yield. The copper-catalyzed acidic ring opening of $1 \mathrm{a}$ with acetate ${ }^{[15]}$ yielded the monofunctionalized derivate 10 in $94 \%$. With nitrogen nucleophiles, such as aniline, the ring opening ${ }^{[16]}$ afforded 11 in $84 \%$ yield. A common additional copper-catalyzed ring closure to phenoxazine derivates could not be conducted under literature known conditions. ${ }^{[16]}$ Copper-catalyzed treatment with mesitylamide yielded pure phenoxazine 12 in $84 \%$. Additional bifunctionalizations were achieved by a sulfur-iodine exchange ${ }^{[17]}$ or by a palladiumcatalyzed carbon-carbon coupling ${ }^{[18]}$ to obtain phenoxathiine 13 in $85 \%$ yield and dibenzofuran 14 in $90 \%$ yield. 


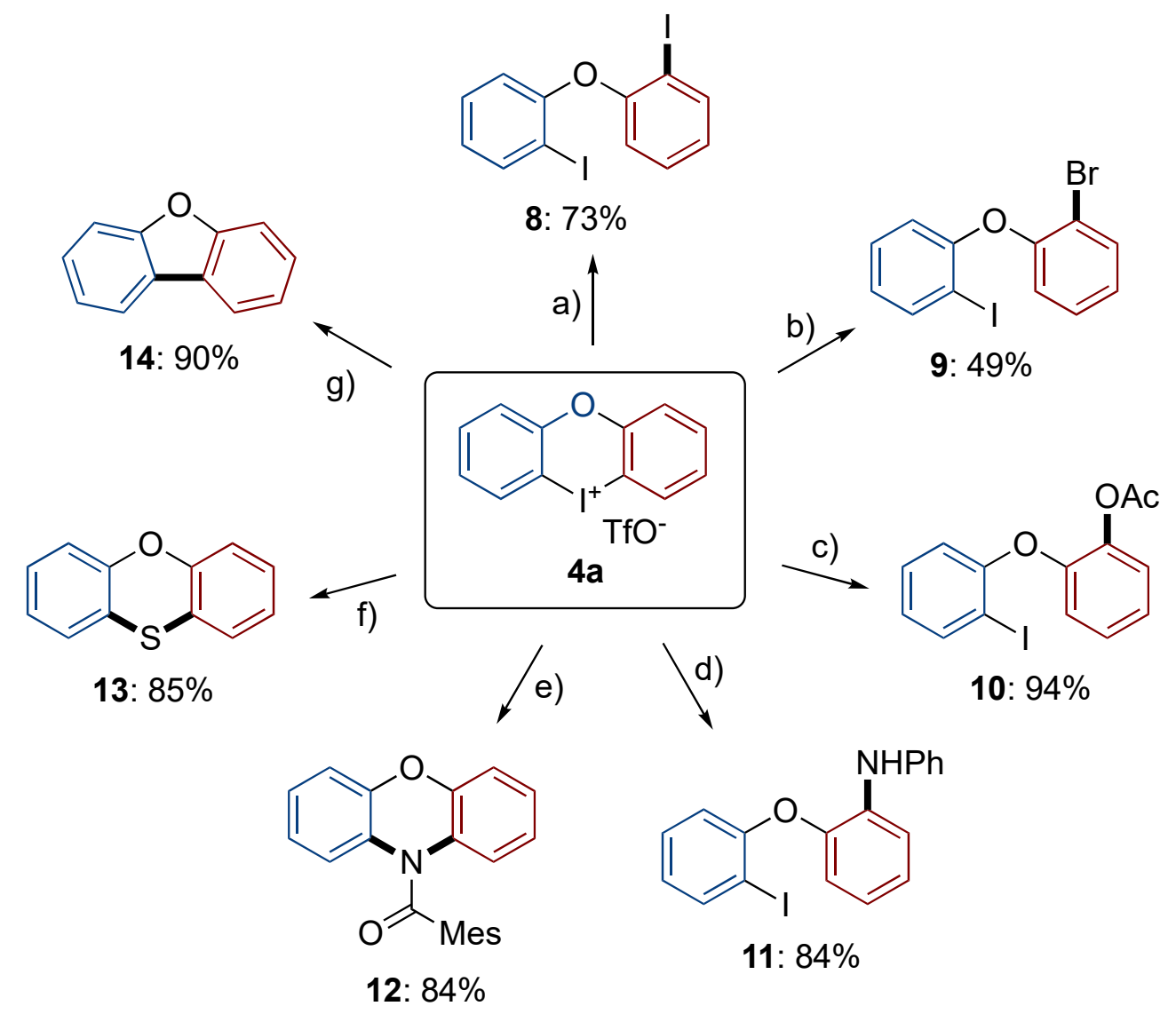

Scheme 4. Representative derivatizations of diaryliodaoxinium triflate $1 \mathbf{a}^{{ }^{a}}$

a Reaction conditions: a) Cul, DMEDA, TBAI, dioxane, rt $-60{ }^{\circ} \mathrm{C}, 48 \mathrm{~h}$; b) (i) $\mathrm{KBr}, \mathrm{H}_{2} \mathrm{O}, \mathrm{EtOH}, 80^{\circ} \mathrm{C}$, $5 \mathrm{~min}$, (ii) $200{ }^{\circ} \mathrm{C}, 5 \mathrm{~min}$; c) NaOAc, $\mathrm{CuSO}_{4} \cdot 5 \mathrm{H}_{2} \mathrm{O}, \mathrm{Ac} 2 \mathrm{O}, \mathrm{AcOH}, 120^{\circ} \mathrm{C}, 24 \mathrm{~h}$; d) $\mathrm{PhNH}_{2}, \mathrm{Cu}(\mathrm{OAc})_{2} \cdot \mathrm{H}_{2} \mathrm{O}$, $\mathrm{Na}_{2} \mathrm{CO}_{3}, \mathrm{PrOH}, 40^{\circ} \mathrm{C}, 22 \mathrm{~h}$; e) $\mathrm{MesCONH}_{2}$, Cul, diglyme, $\mathrm{K}_{2} \mathrm{CO}_{3}, p$-xylene, $120^{\circ} \mathrm{C}, 18 \mathrm{~h}$; f) $\mathrm{KSAc}$, $\mathrm{Cu}(\mathrm{OTf})_{2}$, DMSO, $\left.100^{\circ} \mathrm{C}, 24 \mathrm{~h} ; \mathrm{g}\right) \mathrm{Pd} / \mathrm{C}, \mathrm{NaOAc}, \mathrm{DMA}, 140^{\circ} \mathrm{C}, 24 \mathrm{~h}$.

Finally, the novel iodazinium triflates were also derivatized with similar procedures (Scheme 5). A copper(I)iodide-mediated ring opening of $2 a$ yielded the diiododiphenylamine 15a in a low yield of $14 \%$. A change of the sulfonamide from $\mathrm{N}$ tosyl to $N$-mesyl yielded the desired product $15 \mathrm{~b}$ in a good yield of $77 \%$. The coppercatalyzed ring opening of $\mathbf{2 a}$ with acetate furnished monofunctionalized 16 in $94 \%$ yield. While the yield for the derivatization with aniline significantly dropped compared to the oxygen derivative, the o-diphenylamine 17 could still be obtained in $56 \%$ yield. An additional ring closure to the phenazine could not be observed due to major decomposition at elevated temperatures. Sulfur-iodine exchange reactions ${ }^{[19]}$ of $2 \mathbf{2 a}$ and $\mathbf{2} \mathbf{j}$ afforded the phenothiazines $\mathbf{1 8 a}$ and $\mathbf{1 8 b}$ in $33 \%$ and $60 \%$ yield, respectively. The insertion of oxygen to $\mathbf{2 a}$ only provided traces (4\%) of the desired phenoxazine 19. In contrast, the copper-catalyzed nitrogen functionalization ${ }^{[20]}$ of $2 \mathbf{j}$ with sodium 
azide gave the $N$-deprotected and aromatic phenazine $(20)$ in $62 \%$ yield through azide induced ring opening followed by rearomatization under loss of the mesylate.

We were also intended to performed a literature-known rearrangement of $\mathrm{N}$ sulfonamide-based acyclic iodonium salts. ${ }^{[21]}$ Here, in case of cyclic diaryliodazinium species, the rearrangement product 21 a was obtained in only $27 \%$ yield, while the Mssubstituted derivate $\mathbf{2 1 b}$ could not be observed. To verify the reactivity, the mesityl sulfonamide $\mathbf{2} \mathbf{k}$ gave a significant increase in product formation due to the prevention of side reactions yielding $21 \mathrm{c}$ in $56 \%$.<smiles>[R]N(c1ccccc1I)c1ccccc1I</smiles>

15a: $R=T s, 14 \%$<smiles>[R]c1ccccc1Nc1ccccc1I</smiles>

21a: $\mathrm{R}=\mathrm{C}_{7} \mathrm{H}_{6}, 27 \%$ 21b: $\mathrm{R}=\mathrm{CH}_{3}, 0 \%$ 21c: $R=$ Mes, $56 \%$<smiles>c1ccc2nc3ccccc3nc2c1</smiles>

20: $62 \%$ 15b: $R=M s, 77 \%$

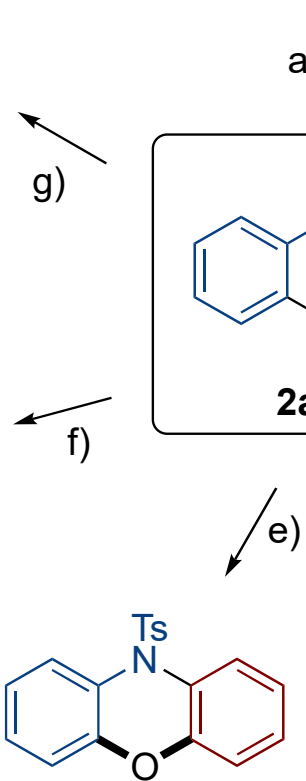

19: $4 \%$ a)<smiles>[CH]1[CH-]CC1</smiles>

(b)

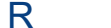

))<smiles>CC(=O)Oc1ccccc1N([125I])c1ccccc1I</smiles>

16: $94 \%$<smiles>ClC(Cl)([Te])c1ccccc1N([123I])c1ccccc1I</smiles>

17: $56 \%$

d)<smiles>[R]N1c2ccccc2Sc2ccccc21</smiles>

18a: $R=T s, 33 \%$ 18b: $R=M s, 60 \%$

Scheme 5. Derivatizations of Diaryliodazinium Triflates $\mathbf{2} \mathbf{a}+\mathbf{j} \mathbf{+} \mathbf{k}^{{ }^{a}}$

a Reaction conditions: a) Cul, DMEDA, TBAI, dioxane, rt, 18 h; b) $\mathrm{NaOAc}, \mathrm{CuSO}_{4} \cdot 5 \mathrm{H}_{2} \mathrm{O}, \mathrm{Ac}_{2} \mathrm{O}, \mathrm{AcOH}$, $120{ }^{\circ} \mathrm{C}, 20 \mathrm{~h}$; c) $\mathrm{PhNH}_{2}, \mathrm{Cu}(\mathrm{OAc})_{2} \cdot \mathrm{H}_{2} \mathrm{O}, \mathrm{Na}_{2} \mathrm{CO}_{3}, \mathrm{PrOH}, 40{ }^{\circ} \mathrm{C}, 24 \mathrm{~h}$; d) $\mathrm{S}_{8}, \mathrm{Cs}_{2} \mathrm{CO}_{3}, \mathrm{DMSO}, 100{ }^{\circ} \mathrm{C}$, $3 \mathrm{~h}$; e) $\mathrm{Cu}(\mathrm{OAc})_{2} \cdot \mathrm{H}_{2} \mathrm{O}$, ethylene glycol, $\mathrm{Na}_{2} \mathrm{CO}_{3}, \mathrm{DMF}, \mathrm{H}_{2} \mathrm{O}, 100{ }^{\circ} \mathrm{C}, 48 \mathrm{~h}$; f) CuTc, $\mathrm{NaN}_{3}, \mathrm{PPh}_{3}, \mathrm{Cs}_{2} \mathrm{CO}$, $\left.\mathrm{H}_{2} \mathrm{O}, \mathrm{DMA}, 120^{\circ} \mathrm{C}, 48 \mathrm{~h} ; \mathrm{g}\right) \mathrm{NEt}_{3}, \mathrm{MeCN}, 80^{\circ} \mathrm{C}, 18 \mathrm{~h}$. 


\section{Summary}

In conclusion, we developed an aryne-based one-pot procedure for the synthesis of iodaoxinium and iodazinium triflates. Initiated by an aryne-mediated metal-free $\mathrm{O}$ - or $\mathrm{N}$-arylation followed by an oxidative cyclization, a variety of o-iodophenols and sulfonamides were successfully transformed into diaryliodaoxinium and diaryliodazinium triflates in high yields. With further derivatizations, a wide range of applications of these mostly unknown iodonium salts was demonstrated. Further derivatizations should be developed for heteroatom-bridged iodonium salts, since they have an altered, albeit interesting reactivity compared to their pure carbon analogs. Deeper investigations towards the reactivity and novel derivatizations using heteroatom-bridged iodonium salts are under current investigation in our laboratories.

\section{Experimental Section}

Detailed optimization studies, experimental procedures, analytical data $\left({ }^{1} \mathrm{H}-,{ }^{13} \mathrm{C}\right.$ - and ${ }^{19} \mathrm{~F}-N M R$-chemical shifts, IR-bands, melting points) including the corresponding NMR-spectra as well as the X-ray data can be found in the supporting information.

\section{References}

1. (a) Caspers, L. D.; Nachtsheim, B. J., Directing-Group-mediated C-HAlkynylations. Chem. Asian J. 2018, 13 (10), 1231-1247; (b) Charpentier, J.; Früh, N.; Togni, A., Electrophilic Trifluoromethylation by Use of Hypervalent lodine Reagents. Chem. Rev. 2015, 115 (2), 650-682; (c) Li, Y.; Hari, D. P.; Vita, M. V.; Waser, J., Cyclic Hypervalent lodine Reagents for Atom-Transfer Reactions: Beyond Trifluoromethylation. Angew. Chem. Int. Ed. Engl. 2016, 55 (14), 4436-54; (d) Yoshimura, A.; Zhdankin, V. V., Advances in Synthetic Applications of Hypervalent lodine Compounds. Chem. Rev. 2016, 116 (5), 3328-435.

2. (a) Maertens, G.; L'Homme, C.; Canesi, S., Total synthesis of natural products using hypervalent iodine reagents. Front. Chem. 2015, 2 (115); (b) Silva, J. L. F.; 
Olofsson, B., Hypervalent iodine reagents in the total synthesis of natural products. Nat. Prod. Rep. 2011, 28 (10), 1722-1754.

3. (a) Abazid, A. H.; Nachtsheim, B. J., A Triazole-Substituted Aryl lodide with Omnipotent Reactivity in Enantioselective Oxidations. Angew. Chem. Int. Ed. 2020, 59 (4), 1479-1484; (b) Abazid, A. H.; Clamor, N.; Nachtsheim, B. J., An Enantioconvergent Benzylic Hydroxylation Using a Chiral Aryl lodide in a Dual Activation Mode. ACS Catalysis 2020, 10 (15), 8042-8048; (c) Boelke, A.; Nachtsheim, B. J., Evolution of N-Heterocycle-Substituted lodoarenes (NHIAs) to Efficient Organocatalysts in lodine(I/III)-Mediated Oxidative Transformations. Adv. Synth. Catal. 2020, 362 (1), 184-191; (d) Parra, A., Chiral Hypervalent lodines: Active Players in Asymmetric Synthesis. Chem. Rev. 2019, 119 (24), 12033-12088; (e) Massignan, L.; Tan, X.; Meyer, T. H.; Kuniyil, R.; Messinis, A. M.; Ackermann, L., C-H Oxygenation Reactions Enabled by Dual Catalysis with Electrogenerated Hypervalent lodine Species and Ruthenium Complexes. Angew. Chem. Int. Ed. 2020, 59 (8), 31843189; (f) Vaillant, F. L.; Waser, J., Decarboxylative Alkynylation and Cyanation of Carboxylic Acids using Photoredox Catalysis and Hypervalent lodine Reagents. Chimia 2017, 71 (4), 226-230; (g) Mukherjee, S.; Garza-Sanchez, R. A.; TlahuextAca, A.; Glorius, F., Alkynylation of C (O)-H Bonds Enabled by Photoredox-Mediated Hydrogen-Atom Transfer. Angew. Chem. Int. Ed. 2017, 56 (46), 14723-14726; (h) Baralle, A.; Fensterbank, L.; Goddard, J.-P.; Ollivier, C., Aryl Radical Formation by Copper(I) Photocatalyzed Reduction of Diaryliodonium Salts: NMR Evidence for a Cull/Cul Mechanism. Chem. Eur. J. 2013, 19 (33), 10809-10813; (i) Heinen, F.; Engelage, E.; Dreger, A.; Weiss, R.; Huber, S. M., lodine(III) Derivatives as Halogen Bonding Organocatalysts. Angew. Chem. Int. Ed. 2018, 57 (14), 3830-3833.

4. (a) Merritt, E. A.; Olofsson, B., Diaryliodonium salts: a journey from obscurity to fame. Angew. Chem. Int. Ed. 2009, 48 (48), 9052-70; (b) Novák, Z.; Aradi, K.; Tóth, B.; Tolnai, G., Diaryliodonium Salts in Organic Syntheses: A Useful Compound Class for Novel Arylation Strategies. Synlett 2016, 27 (10), 1456-1485.

5. (a) Chatterjee, N.; Goswami, A., Synthesis and Application of Cyclic Diaryliodonium Salts: A Platform for Bifunctionalization in a Single Step. Eur. J. Org. Chem. 2017, 2017 (21), 3023-3032; (b) Grushin, V. V., Cyclic diaryliodonium ions: old mysteries solved and new applications envisaged. Chem. Soc. Rev. 2000, 29 (5), 315324. 
6. Beringer, F. M.; Kravetz, L.; Topliss, G. B., lodonium Salts Containing Heterocyclic lodine1-3. J. Org. Chem. 1965, 30 (4), 1141-1148.

7. Luo, B.; Cui, Q.; Luo, H.; Hu, Y.; Huang, P.; Wen, S., N-Benzyldithiocarbamate Salts as Sulfur Sources to Access Tricyclic Thioheterocycles Mediated by Copper Species. Adv. Synth. Catal. 2016, 358 (17), 2733-2738.

8. Reinhard, D. L.; Heinen, F.; Stoesser, J.; Engelage, E.; Huber, S. M., Tuning the Halogen Bonding Strength of Cyclic Diaryliodonium Salts. Helv. Chim. Acta 2021, 104 (2), e2000221.

9. Caspers, L. D.; Spils, J.; Damrath, M.; Lork, E.; Nachtsheim, B. J., One-Pot Synthesis and Conformational Analysis of Six-Membered Cyclic lodonium Salts. J. Org. Chem. 2020, 85 (14), 9161-9178.

10. (a) Shi, J.; Li, L.; Li, Y., o-Silylaryl Triflates: A Journey of Kobayashi Aryne Precursors. Chemical Reviews 2021, 121 (7), 3892-4044; (b) Sanz, R., RECENT APPLICATIONS OF ARYNE CHEMISTRY TO ORGANIC SYNTHESIS. A REVIEW. Org. Prep. Proced. Int. 2008, 40 (3), 215-291; (c) Wenk, H. H.; Winkler, M.; Sander, W., One Century of Aryne Chemistry. Angew. Chem. Int. Ed. 2003, 42 (5), 502-528.

11. Liu, Z.; Larock, R. C., Facile N-Arylation of Amines and Sulfonamides and OArylation of Phenols and Arenecarboxylic Acids. J. Org. Chem. 2006, 71 (8), 31983209.

12. Wu, B.; Yoshikai, N., Conversion of 2-lodobiaryls into 2,2'-Diiodobiaryls via Oxidation-lodination Sequences: A Versatile Route to Ladder-Type Heterofluorenes. Angew. Chem. Int. Ed. 2015, 127 (30), 8860-8863.

13. Karele, B. Y.; Kalnin, S. V.; Grinberga, I. P.; Neiland, O. Y., lodonium derivatives of heterocyclic compounds. Chem. Heterocycl. Compd. 1973, 9 (2), 226229.

14. Tolstaya, T. P.; Egorova, L. D.; Lisichkina, I. N., Oxidative cyclization of halobenzophenone oximes to 4,2'-iodonia-3-phenyl-1,2-benzisoxazole salts. Chem. Heterocycl. Compd. 1985, 21 (4), 392-396.

15. Hu, Z.; Tang, Y.; Yu, B., Glycosylation with 3,5-Dimethyl-4-(2'phenylethynylphenyl)phenyl (EPP) Glycosides via a Dearomative Activation Mechanism. J. Am. Chem. Soc. 2019, 141 (12), 4806-4810.

16. Zhu, D.; Liu, Q.; Luo, B.; Chen, M.; Pi, R.; Huang, P.; Wen, S., Synthesis of Carbazoles via One-Pot Copper-Catalyzed Amine Insertion into Cyclic 
Diphenyleneiodoniums as a Strategy to Generate a Drug-Like Chemical Library. Adv. Synth. Catal. 2013, 355 (11-12), 2172-2178.

17. Shimizu, M.; Ogawa, M.; Tamagawa, T.; Shigitani, R.; Nakatani, M.; Nakano, Y., Copper-Catalyzed Double S-Arylation of Potassium Thioacetate with Dibenziodolium Triflates: Facile Synthesis of Unsymmetrical Dibenzothiophenes. Eur. J. Org. Chem. 2016, 2016 (16), 2785-2788.

18. Panda, N.; Mattan, I.; Nayak, D. K., Synthesis of Dibenzofurans via C-H Activation of o-lodo Diaryl Ethers. J. Org. Chem. 2015, 80 (13), 6590-6597.

19. Wang, M.; Fan, Q.; Jiang, X., Transition-Metal-Free Diarylannulated Sulfide and Selenide Construction via Radical/Anion-Mediated Sulfur-Iodine and Selenium-lodine Exchange. Org. Lett. 2016, 18 (21), 5756-5759.

20. Wang, M.; Fan, Q.; Jiang, X., Nitrogen-lodine Exchange of Diaryliodonium Salts: Access to Acridine and Carbazole. Org. Lett. 2018, 20 (1), 216-219.

21. Chen, H.; Wang, L.; Han, J., Aryl radical-induced desulfonylative ipsosubstitution of diaryliodonium salts: an efficient route to sterically hindered biarylamines. Chem. Commun. 2020, 56 (42), 5697-5700. 